\title{
Energy Self-Sufficiency Conditions of Ethanol Autothermal Reforming: a Simulation Study
}

\author{
Marcos Lapa Brito ${ }^{1}$ \\ https://orcid.org/0000-0001-5707-7437 \\ Caetano Maraes ${ }^{2}$ \\ https://orcid.org/0000-0002-3003-3159 \\ Luiz Carlos Lobato dos Santos 1 \\ https://orcid.org/0000-0003-3824-7802
}

\section{George Simonelli ${ }^{1 *}$}

https://orcid.org/0000-0002-8031-1401

\begin{abstract}
${ }^{1}$ Federal University of Bahia, Oil, Gas and Biofuels Research Group, Postgraduate Program of Chemical Engineering, Federação, Salvador, Bahia, Brazil; ${ }^{2}$ Federal University of Rio de Janeiro, Department of Chemical Engineering, Ilha do Fundão, Rio de Janeiro, Brasil.
\end{abstract}

Editor-in-Chief: Alexandre Rasi Aoki

Associate Editor: Ana Cláudia Barana

Received: 2021.01.26; Accepted: 2021.04.05.

*Correspondence: gsimonelli@ufba.br; Tel.: +55-71-32839854 (G.S.).

\section{HIGHLIGHTS}

- Pressure is not statistically significant for ethanol autothermal reforming.

- Temperature and steam/ethanol ratio have a positive effect on hydrogen production.

- Autothermal Reactor can achieve energy self-sufficiency.

\begin{abstract}
Natural gas steam reforming is commonly used for hydrogen production. However, research has shown that ethanol autothermal reforming can produce cleaner hydrogen gas efficiently. Despite this, there is a lack of studies on the energy self-sufficiency conditions of the ethanol autothermal reform. In this paper, we use simulations and the Response Surface Methodology (RSM) for the multivariate analysis of the energy self-sufficiency conditions in this process. First, we constructed and validated an industrial flowchart. After that, RSM allowed us to assess the process variables effects. The process variables studied were temperature ( 0 to $\left.1000^{\circ} \mathrm{C}\right)$, pressure (20 to $30 \mathrm{bar}$ ), steam/ethanol ratio $(2$ to $5 \mathrm{~mol} / \mathrm{mol})$ and $\mathrm{O}_{2} /$ ethanol ratio ( 0 to $1.5 \mathrm{~mol} / \mathrm{mol}$ ). We observe that the temperature and steam/ethanol ratio increase have a positive effect on hydrogen production. On the contrary, the $\mathrm{O}_{2}$ /ethanol ratio increase has a negative effect, and the pressure increase is not statistically significant on hydrogen production. Therefore, the pressure was used at its minimum level (20 bar) while the temperature and the steam/ethanol ratio at its maximum levels $\left(1000{ }^{\circ} \mathrm{C}\right.$ and $5 \mathrm{~mol} / \mathrm{mol}$ ). We also evaluated the energy consumption for the Autothermal Reactor (ATR). The reactor consumed $477.92 \mathrm{~kJ} / \mathrm{mol}$ ethanol to produce $5.12 \mathrm{~mol} \mathrm{H} / 2 / \mathrm{mol}$ ethanol when we use $1000 \stackrel{\circ}{\circ} \mathrm{C}, 20$ bar, steam/ethanol $5 \mathrm{~mol} / \mathrm{mol}$, and $\mathrm{O}_{2} /$ ethanol $0 \mathrm{~mol} / \mathrm{mol}$. ATR's energy self-sufficiency is achieved by using $1000 \stackrel{\circ}{\circ}, 20 \mathrm{bar}$, steam/ethanol $5 \mathrm{~mol} / \mathrm{mol}$, and $\mathrm{O}_{2} /$ ethanol $0.86 \mathrm{~mol} / \mathrm{mol}$. In these conditions, $3.95 \mathrm{~mol} \mathrm{H} / \mathrm{mol}$ ethanol is produced with $0 \mathrm{~kJ} / \mathrm{mol}$ ethanol.
\end{abstract}


Keywords: Hydrogen gas production; modeling and simulation; renewable energy generation.

\section{INTRODUCTION}

Energy is a resource closely linked to the excellent performance of contemporary socioeconomic activities. Nevertheless, it is estimated that more than $80 \%$ of the global energy matrix is supplied by fossil fuels, like for example, oil, natural gas, and mineral coal $[1,2,3]$. Despite the practical and energetic advantages of fossil fuels, their excessive consumption brings problems, such as the generation of gases intensifying the greenhouse effect and air pollution. Besides that, due to its scarcity over the years, a probable energy crisis might be another problem $[1,4,5]$. The disadvantages of fossil resources and the growth of environmental awareness drive the development of clean and efficient technologies and fuels $[6,7]$. In this context, gas hydrogen is an alternative to traditional fuels due to five characteristics [1,5]:

a. It has the highest energy density among the known substances $(120 \mathrm{MJ} / \mathrm{kg})$;

b. It can be produced from different sources (including renewable sources as water and biomass);

c. It is sustainable;

d. It is not toxic;

e. It has clean burning (releases only water).

The five characteristics mentioned have attracted the attention of scientists. Since 1970, the "Hydrogen Economics" studies relate the production, use, transportation, and storage of hydrogen to the construction of a scenario in which this fuel is a primary source of energy. This scenario can promote high energy efficiency and reductions in environmental impacts and $\mathrm{CO}_{2}$ emissions [1,5]. The hydrogen production to contribute to the global energy matrix decarbonization can be done from various methodologies. Some methodologies are natural gas steam reforming, coal gasification, water electrolysis, photocatalysis, and alcohol reform [4]. Regardless of the methods, the key to large-scale hydrogen production is to cheapen raw materials and the process as a whole $[1,2,4]$.

Hydrogen is the most abundant element in the universe. Despite this, it is little found on Earth in its gaseous form because it is usually associated with water and hydrocarbons [8]. Although there are many ways to produce hydrogen gas, $90 \%$ of production uses non-renewable raw materials, with natural gas being the primary raw material [9-11]. It is estimated that the natural gas steam reform, due to its high concentration of methane, exceeds $500,000 \mathrm{~kg} \mathrm{H}_{2} /$ day $[9,12]$. Steam reform consists of a highly reactive endothermic reaction of natural gas with steam. High temperatures favor this reaction. The increase in the amount of steam also favors the reaction. However, increasing the temperature and the steam amount require higher costs in reactor operation and steam production, respectively. Therefore, a ratio of around 2.5-5.5 steam/methane is commonly used in refineries [9,12,13].

Ethanol as well as methane can be used to produce hydrogen. Inside a reforming reactor, ethanol is decomposed into methane, carbon monoxide and hydrogen, according to Equation 1. The combination of ethanol partial oxidation, Equation 2, which is extremely exothermic, and the ethanol reforming, Equations 3 and 4, produces the ethanol autothermal reforming, Equation 5. This is an alternative technology to achieve sustainable hydrogen production. Therefore, this methodology has a lower environmental impact and can achieve energy self-sufficiency $[9,14,15]$. Most studies on ethanol autothermal reform were concerned with the structural part of the reactors $[16,17]$ and the development of cheap and efficient catalysts for the process [18-20]. Few studies in the scientific literature evaluate the ethanol autothermal reform based on modeling and simulation [21]. However, the modeling and simulation processes are useful tools for decision making, since they allow us to study the behavior of the process, as well as to evaluate and compare the impacts of operational conditions [22]. Also, it is essential to multivariate analysis, based on statistics, to determine which independent variables most affect the process, as well as to generate mathematical models to assess operational conditions [23]. In this work, multivariate statistical analysis was used to determine the energy self-sufficiency conditions of the ethanol autothermal reform. There is no knowledge in the literature of the energy self-sufficiency conditions in this process.

Some authors $[24,25]$ have presented studies on the thermodynamic behavior of hydrogen production concerning temperature, steam/ethanol ratio, and $\mathrm{O}_{2} /$ ethanol ratio. These studies use Equations of State and univariate analyzes of the operational conditions of the process [24,25]. Both Graschinsky and coauthors. [24] and Rabenstein and Hacker [25] performed simulations varying the temperature, the steam/ethanol ratio, and the $\mathrm{O}_{2} /$ ethanol ratio to study the behavior of hydrogen production. However, to the best of our knowledge, 
the simulations performed did not rely on multivariate analysis, limiting the understanding of the process, since the univariate analysis does not allow us to assess whether the process variables interact with each other. Besides, these studies did not take into account the process pressure variations, which is also one of its operational conditions. As the global reaction of the ethanol autothermal reforming does not have the same number of moles on the side of reagents and products, according to Le Chatelier's principle, it is expected that pressure variations affect the reaction equilibrium [26].

In this paper, we use simulations and the Response Surface Methodology (RSM) to assess the influence of temperature, pressure, steam/ethanol ratio, and $\mathrm{O}_{2}$ /ethanol ratio on the ethanol autothermal reforming. RSM is a collection of statistical and mathematical techniques that can be applied in the optimization and approximation of first- and second-order response surface models. The independent variables (control factors) are the input, and the outputs are the dependent variables (or response variable). In this work, RSM allowed us to determine the statistical significance of the controlled variables. Also, it was used to study the interaction effects of the parameters and to obtain a mathematical relationship between control variables (temperature, pressure, steam/ethanol ratio, and $\mathrm{O}_{2} /$ ethanol ratio) and responses (hydrogen production and energy consumption).

\section{MATERIAL AND METHODS}

\section{Choice of Software and Thermodynamic Package}

The construction of the flowcharts of the ethanol autothermal reform plant, as well as their simulations, were performed using the Aspen HYSYS V9 software, which is widely used in research and the industrial field for the study of chemical processes. Regarding the thermodynamic package, UNIQUAC was chosen, due to the polarity presented by the ethanol molecule.

\section{Determination of reagents}

In the simulations of the reforming plant, pure streams of ethanol, steam, and oxygen were used. The flow rate of ethanol used in each simulation was $100 \mathrm{kmol} / \mathrm{h}$. The steam flow rate used was $200 \mathrm{kmol} / \mathrm{h}$, and for the oxygen, the flow rate was $100 \mathrm{kmol} / \mathrm{h}$. All reagent streams were initially simulated under pressure and temperature conditions equal to 20 bar and $300^{\circ} \mathrm{C}$, respectively.

\section{Construction of the flowchart of the ethanol autothermal reforming}

The ethanol autothermal reforming is not yet used in the industry for the production of hydrogen. Therefore, its process flowchart was built based on the existing steps for the steam reform of natural gas [13] and suggested by Vita and coauthors [9] considering only the stages of reform and the water displacement reaction. The simulations of the ethanol autothermal reform were carried out according to the flowchart shown in Figure 1. 


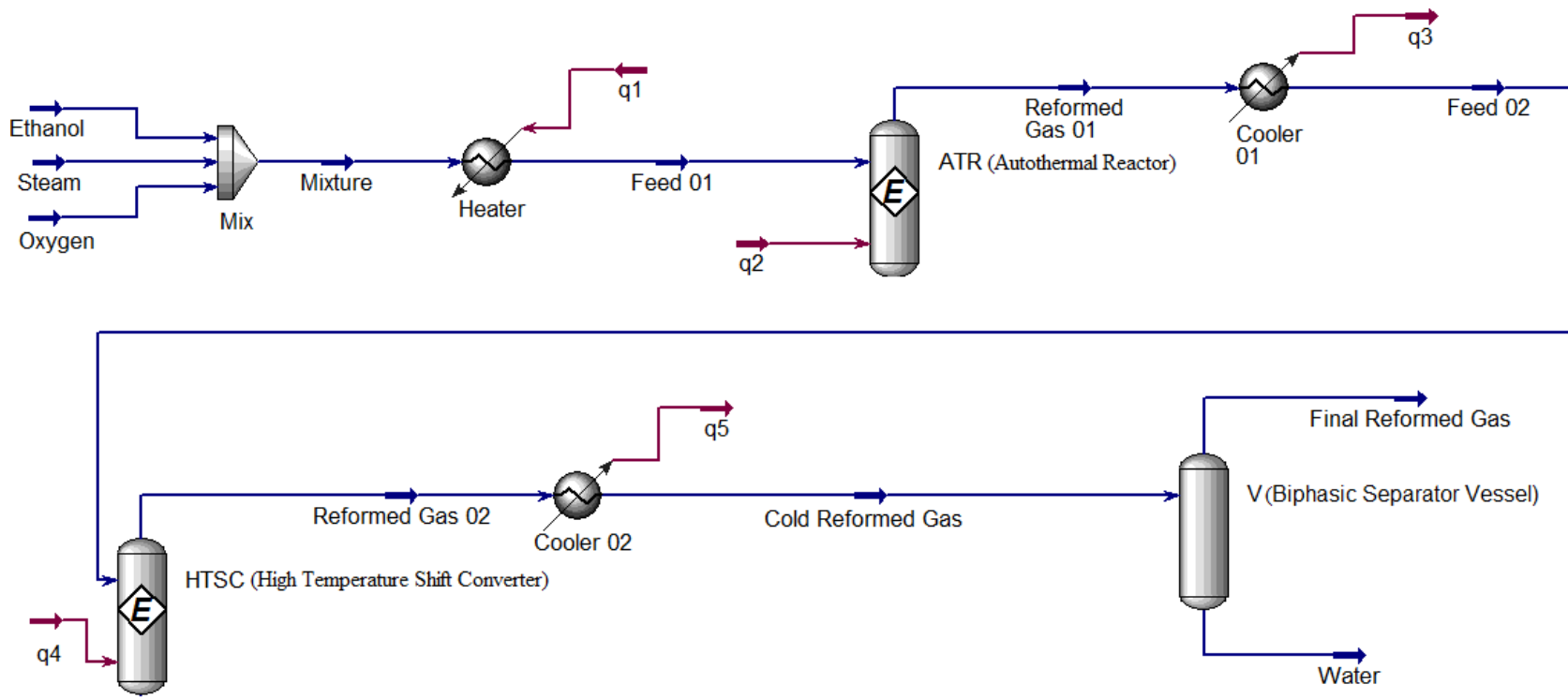

Figure 1. Flowchart for the ethanol autothermal reform plan built on Aspen HYSYS. The currents q1 to q5 represent the energy flows involved in the heating and cooling processes of the material currents in the process.

The supply of the ATR (Autothermal Reactor) is a mixture of ethanol, steam, and oxygen that was heated by the Heater to $500 \stackrel{\circ}{ } \mathrm{C}$. When ethanol enters the ATR, it can be decomposed according to the reaction of Equation 1. In contrast, reactions showed in Equations 2, 3, and 4 occur in parallel, and correspond to partial oxidation of ethanol, the reform of methane, and the conversion of carbon monoxide to carbon dioxide that is known as Water-Gas Shift (WGS), respectively. Equation 5 represents the global balance of ethanol autothermal reforming.

$$
\begin{gathered}
\mathrm{C}_{2} \mathrm{H}_{5} \mathrm{OH}(g) \leftrightarrow \mathrm{CH}_{4}(g)+\mathrm{CO}(g)+\mathrm{H}_{2}(g), \\
\mathrm{C}_{2} \mathrm{H}_{5} \mathrm{OH}(g)+3 / 2 \mathrm{O}_{2}(g) \rightarrow 3 \mathrm{H}_{2}(g)+2 \mathrm{CO}_{2}(g), \quad \Delta H=-549 \mathrm{~kJ} / \mathrm{mol}, \\
\mathrm{CH}_{4}(g)+\mathrm{H}_{2} \mathrm{O}(g) \rightleftharpoons \mathrm{CO}(g)+3 \mathrm{H}_{2}(g), \quad \Delta H=+206 \mathrm{~kJ} / \mathrm{mol}, \\
\mathrm{CO}(g)+\mathrm{H}_{2} \mathrm{O}(g) \rightleftharpoons \mathrm{CO}_{2}(g)+\mathrm{H}_{2}(g), \quad \Delta \mathrm{H}=-41 \mathrm{~kJ} / \mathrm{mol}, \\
\mathrm{C}_{2} \mathrm{H}_{5} \mathrm{OH}(g)+x \mathrm{O}_{2}+(3-2 x) \mathrm{H}_{2} \mathrm{O} \rightleftharpoons(6-2 x) \mathrm{H}_{2}+2 \mathrm{CO}_{2}
\end{gathered}
$$

From the analysis of Equation 5, it is clear that the amount of oxygen used in the process has a direct impact on the production of hydrogen. Since Equation 4 is exothermic, the ATR product passes through Cooler 01 to be cooled to $500{ }^{\circ} \mathrm{C}$, going to the HTSC (High-Temperature Shift Converter), whose function is to react methane and carbon monoxide with steam to produce more hydrogen. The HTSC was operated at a fixed temperature of $500 \stackrel{\circ}{\circ}$. After this step, Reformed Gas 02 passes through Cooler 02 , to be cooled to room temperature. Water is separated in a Biphasic Separator Vessel (V), from which Water and the Final Reformed Gas come out. The Final Reformed Gas has a high concentration of hydrogen and carbon dioxide. The equilibrium constants of the reactions performed in the flowchart of Figure 1 were calculated from the minimization of Gibbs Free Energy.

\section{Validation of the flowchart of the ethanol autothermal reforming}

In order to validate the proposed flowchart for the ethanol autothermal reforming, as shown in Figure 1, we carried out simulations, varying the reforming temperature and the flow rates of the reagents. These simulations were performed according to the work of Rabenstein and Hacker [25].

\section{Statistical analysis of operational conditions}

We investigated the statistical significance of four factors (temperature, pressure, steam/ethanol ratio, and O2/ethanol ratio) of the ethanol autothermal reforming, as shown in Table 1. 
Table 1. Factorial Design - Coded and real values for the variables of the ethanol autothermal reforming.

\begin{tabular}{lrrr}
\hline Factors/Codes & \multicolumn{1}{c}{} & $\mathbf{0}$ & \multicolumn{1}{c}{$\mathbf{+ 1}$} \\
\hline Temperature $\left({ }^{\circ} \mathrm{C}\right)$ & 600.00 & 800.00 & 1000.00 \\
Pressure $(\mathrm{bar})$ & 20.00 & 25.00 & 30.00 \\
Steam/ethanol $(\mathrm{mol} / \mathrm{mol})$ & 2.00 & 3.50 & 5.00 \\
O $_{2} /$ ethanol $(\mathrm{mol} / \mathrm{mol})$ & 0.00 & 0.75 & 1.50 \\
\hline
\end{tabular}

Our factorial design was complete for two levels of each factor. In total, 17 simulations (with one central point) were performed. The values of the indicators were defined based on the operating conditions of an industrial reforming process $[13,16]$.

In this paper, the statistical analyses were made from the assessment of the estimated effect tables and Pareto graphs. We use a confidence level of $95 \%$ to assess the significance of the operational conditions studied in the production of hydrogen and energy consumption. Besides that, we also obtain mathematical models for hydrogen consumption and energy consumption in ATR. Based on the ANOVA of these models, we performed the $F$ test to prove the significance of the models and thus evaluate the point of better hydrogen production and the energy self-sufficiency of the ATR.

\section{RESULTS AND DISCUSSION}

\section{Validation of the flowchart of the ethanol autothermal reforming}

Rabenstein and Hacker [25] carried out a thermodynamic study that evaluated the production of hydrogen as a function of the operational conditions of the ethanol autothermal reforming (temperature, steam/ethanol ratio, and O2/ethanol ratio). The results were obtained from the Peng-Robinson and Gibbs Free Energy Minimization equations. The calculations were performed at Aspen-Tech. The variables were studied in the ranges of $200{ }^{\circ} \mathrm{C}$ to $1000{ }^{\circ} \mathrm{C} ; 0$ to $10(\mathrm{~mol} / \mathrm{mol})$ and 0 to $0.75(\mathrm{~mol} / \mathrm{mol})$, for temperature, steam/ethanol ratio, and $\mathrm{O} 2 / \mathrm{ethanol}$ ratio, respectively, at atmospheric pressure. These same conditions were reproduced in this study with the Aspen HYSYS software using the UNIQUAC thermodynamic package. Figure 2 shows the results obtained in this study. 

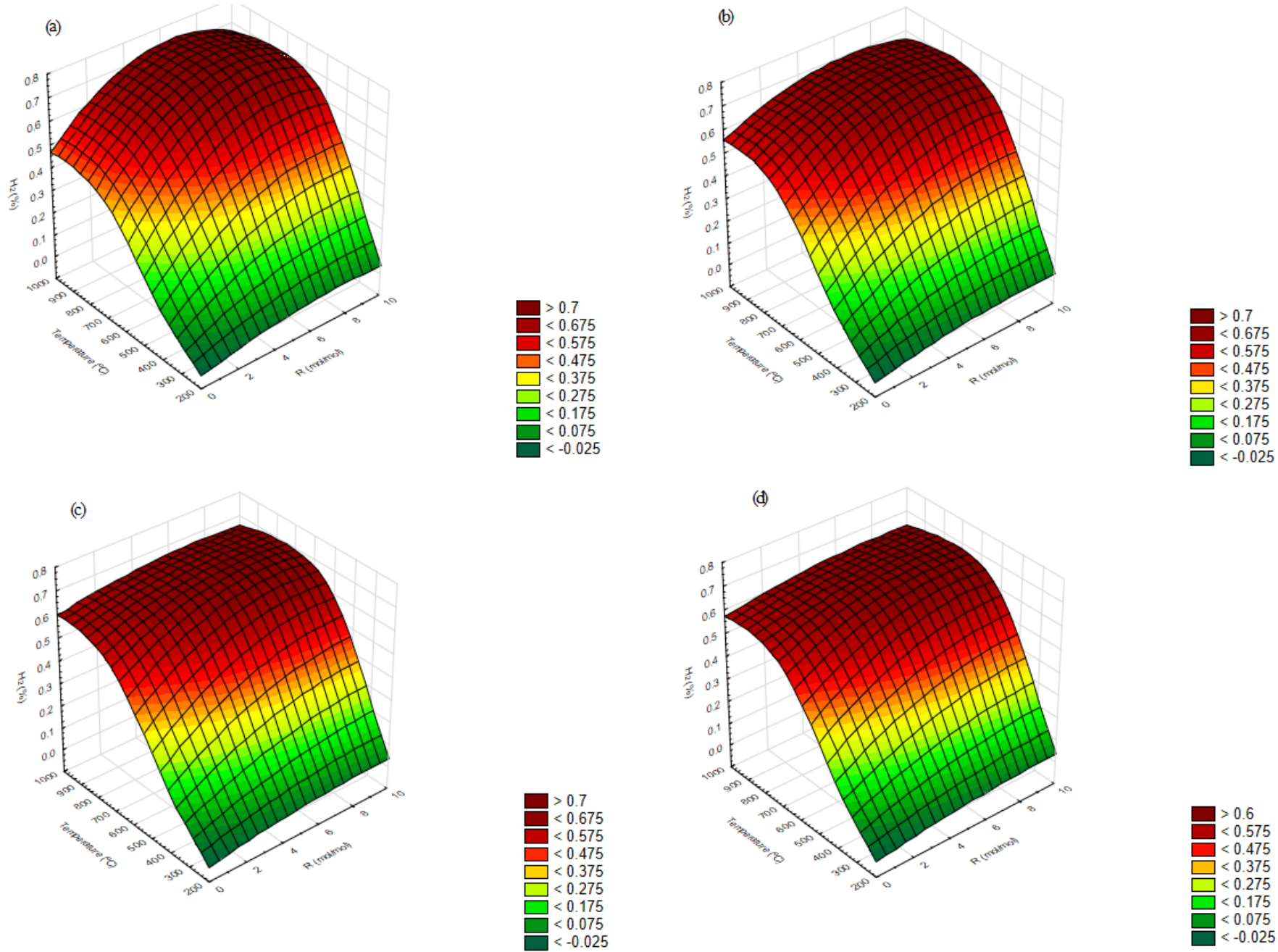

Figure 2. Results of the simulations for the molar fraction of $\mathrm{H}_{2}$ as a function of temperature and steam/ethanol ratio $(\mathrm{R})$, obtained in Aspen HYSYS. (a) $\left(\mathrm{O}_{2} /\right.$ ethanol $)=0$; (b) $\left(\mathrm{O}_{2} /\right.$ ethanol $)=0.25$; (c) $\left(\mathrm{O}_{2} /\right.$ ethanol $)=0.50 ;(d)\left(\mathrm{O}_{2} /\right.$ ethanol $)=$ 0.75 .

The results found in this study (Figure 2) were similar to those obtained by Rabenstein and Hacker [25]. Therefore, we concluded that the flowchart presented in Figure 1 is valid and can be used to study the ethanol autothermal reform. The behaviors obtained in Figure 2 are following Eqs. 3 and 4. The increase of temperature and the steam/ethanol ratio favors hydrogen production. This occurs because Equation 3 (methane reforming) is an endothermic reaction. Therefore, high temperatures favor it. Also, Equation 4 shows that excess water steam contributes to the conversion of $\mathrm{CO}$ to $\mathrm{H} 2$. In contrast, increasing O2/ethanol ratio reduces hydrogen production according to Equation 5 . This decrease in hydrogen production occurs because higher amounts of oxygen favor more the partial oxidation of ethanol than the reform reaction. It is perceived in Equation 2 that the ethanol partial oxidation produces 3 hydrogen mols while its reforming can produce 6 hydrogen mols, according to Equation 5 in absence of oxygen.

\section{Statistical analysis of the influence of the operational parameters of the ethanol autothermal reforming}

We use a complete factorial design (temperature, pressure, steam/ethanol ratio, and O2/ethanol ratio) to determine which variables are statistically significant for ethanol autothermal reforming. The simulated conditions are shown in Table 2, together with the results of hydrogen production and energy consumption. 
Table 2. Matrix of planning of 4 factors and results of the simulations - Ethanol Reforming

\begin{tabular}{ccccccc}
\hline Simulations & $\mathbf{T}\left({ }^{\circ} \mathbf{C}\right)$ & $\mathbf{P}(\mathbf{b a r})$ & $\begin{array}{c}\mathbf{R}^{\star} \\
(\mathbf{m o l} / \mathbf{m o l})\end{array}$ & $\begin{array}{c}\mathbf{R} \mathbf{O}^{\star *} \\
(\mathbf{m o l} / \mathbf{m o l})\end{array}$ & $\begin{array}{c}\mathbf{m o l H}_{2} / \mathbf{m o l} \\
\text { ethanol }\end{array}$ & $\begin{array}{c}\mathbf{E}(\mathbf{k J} / \mathbf{m o l} \\
\text { ethanol) }\end{array}$ \\
\hline 1 & 600 & 20.00 & 2.00 & 0.00 & 0.84 & -8.19 \\
2 & 1000 & 20.00 & 2.00 & 0.00 & 4.30 & 357.12 \\
3 & 600 & 30.00 & 2.00 & 0.00 & 0.70 & -15.85 \\
4 & 1000 & 30.00 & 2.00 & 0.00 & 4.08 & 337.82 \\
5 & 600 & 20.00 & 5.00 & 0.00 & 1.58 & 38.12 \\
6 & 1000 & 20.00 & 5.00 & 0.00 & 5.37 & 430.92 \\
7 & 600 & 30.00 & 5.00 & 0.00 & 1.33 & 25.62 \\
8 & 1000 & 30.00 & 5.00 & 0.00 & 5.29 & 426.96 \\
9 & 600 & 20.00 & 2.00 & 1.50 & 0.89 & -600.48 \\
10 & 1000 & 20.00 & 2.00 & 1.50 & 2.64 & -362.16 \\
11 & 600 & 30.00 & 2.00 & 1.50 & 0.74 & -609.12 \\
12 & 1000 & 30.00 & 2.00 & 1.50 & 2.63 & -362.52 \\
13 & 600 & 20.00 & 5.00 & 1.50 & 1.35 & -567.72 \\
14 & 1000 & 20.00 & 5.00 & 1.50 & 2.81 & -307.15 \\
15 & 600 & 30.00 & 5.00 & 1.50 & 1.15 & -578.52 \\
16 & 1000 & 30.00 & 5.00 & 1.50 & 2.81 & -306.54 \\
17 & 800 & 25.00 & 3.50 & 0.75 & 3.30 & 208.01 \\
\hline
\end{tabular}

*Steam/ethanol ratio; ** Oxygen/ethanol ratio

From the statistical analyzes, we generated the Pareto graphs for hydrogen production and energy consumption in the ATR, as shown in Figure 3.

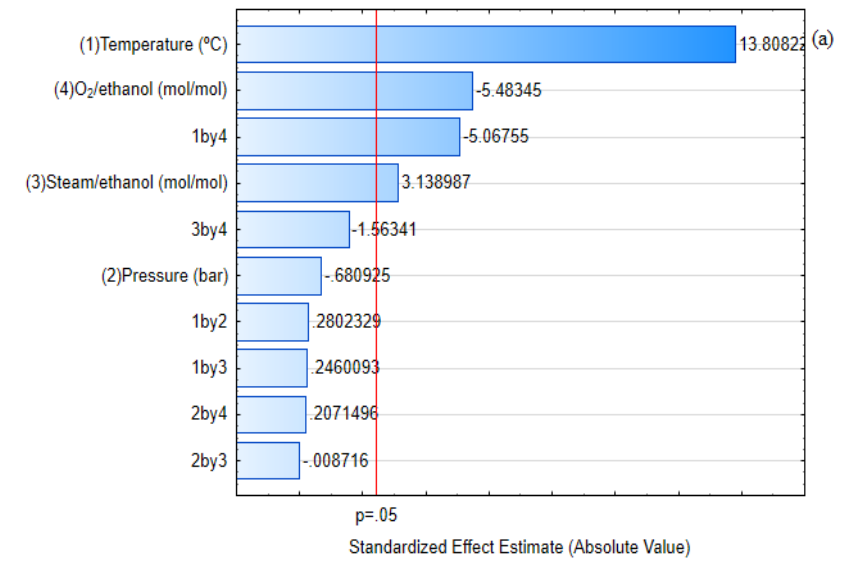

Figure 3. Pareto graph for the factorial design of four factors. (a) $\mathrm{H}_{2}$ production; (b) Energy consumption in the ATR.

We noticed that the increasing temperature and the steam/ethanol ratio favor hydrogen production (Figure 3.a) and increase the ATR energy consumption (Figure 3.b). In contrast, increasing the pressure and O2/ethanol ratio decreases the ATR energy consumption (Figure 3.b) and the production of hydrogen (Figure 3.a). Still, based on Figure 3, we noticed that the pressure was not statistically significant for the production of hydrogen or the consumption of energy in the ATR. Therefore, it can be set at its minimum level (20 bar), without impairing the production of hydrogen. Besides, lower pressure values are safer in industrial operations. The temperature, steam/ethanol ratio, and O2/ethanol ratio were statistically significant for the production of hydrogen (Figure 3.a). There was also a negative interaction between temperature and the O2/ethanol ratio. This result means that different levels of these variables $(+1$ and -1 or -1 and +1 , respectively) can be used to increase hydrogen production. For the ATR energy consumption, only the temperature and $\mathrm{O} 2 /$ ethanol ratio were statistically significant. Based on the statistical analysis, we generate the estimated effects of the factors on hydrogen production, according to Table 3. 
Table 3. Estimated effects for hydrogen production

\begin{tabular}{cccccc}
\hline Factor & Effect & Std.Err. & $\mathbf{p}$ & $\mathbf{- 9 5 \%}$ & $\mathbf{+ 9 5 \%}$ \\
\hline (1) Temperature $\left({ }^{\circ} \mathrm{C}\right)$ & 2.668 & 0.193 & 0.000 & 2.196 & 3.141 \\
(2) Pressure $($ bar) & -0.132 & 0.193 & 0.521 & -0.604 & 0.341 \\
(3) Steam/ethanol $(\mathrm{mol} / \mathrm{mol})$ & 0.607 & 0.193 & 0.020 & 0.134 & 1.079 \\
(4) $\mathrm{O}_{2} /$ ethanol $(\mathrm{mol} / \mathrm{mol})$ & -1.060 & 0.193 & 0.002 & -1.532 & -0.587 \\
1 by 2 & 0.054 & 0.193 & 0.789 & -0.419 & 0.527 \\
1 by 3 & 0.048 & 0.193 & 0.814 & -0.425 & 0.520 \\
1 by 4 & -0.979 & 0.193 & 0.002 & -1.452 & -0.506 \\
2 by 3 & -0.002 & 0.193 & 0.993 & -0.474 & 0.471 \\
2 by 4 & 0.040 & 0.193 & 0.843 & -0.432 & 0.513 \\
3 by 4 & -0.302 & 0.193 & 0.169 & -0.775 & 0.171 \\
\hline
\end{tabular}

Std.Err. (Standard Error), $\mathrm{p}$ ( $\mathrm{p}$-values).

The evaluation of the estimated effects for hydrogen production indicates that the steam/ethanol ratio has a positive effect on it. Thus, the use of this operational condition at its maximum level $(5 \mathrm{~mol} / \mathrm{mol})$ will favor production. However, the temperature and the O2/ethanol ratio showed a significant negative interaction. The negative interaction means that the temperature and the O2/ethanol ratio must not be analyzed separately. Therefore, using temperature and oxygen/ethanol ratio at different levels $(+1$ and -1 or -1 and +1 ) favor hydrogen production. The pressure was not statistically significant, and it can be used at its minimum level (20 bar). Table 4 shows the estimated effects of ATR energy consumption.

Table 4. Estimated effects for energy consumption on ATR

\begin{tabular}{cccccc}
\hline Factor & Effect & Std.Err. & $\mathbf{p}$ & $\mathbf{- 9 5 \%}$ & $\mathbf{+ 9 5 \%}$ \\
\hline (1) Temperature $\left({ }^{\circ} \mathrm{C}\right)$ & 316.323 & 67.248 & 0.003 & 151.775 & 480.872 \\
(2) Pressure $(\mathrm{bar})$ & -7.825 & 67.248 & 0.911 & -172.374 & 156.724 \\
(3) Steam/ethanol $(\mathrm{mol} / \mathrm{mol})$ & 53.134 & 67.248 & 0.460 & -111.415 & 217.683 \\
(4) $\mathrm{O}_{2} /$ ethanol $(\mathrm{mol} / \mathrm{mol})$ & -660.845 & 67.248 & 0.000 & -825.394 & -496.296 \\
1 by 2 & 2.074 & 67.248 & 0.976 & -162.475 & 166.623 \\
1 by 3 & 15.347 & 67.248 & 0.827 & -149.202 & 179.896 \\
1 by 4 & -61.956 & 67.248 & 0.392 & -226.505 & 102.593 \\
2 by 3 & 1.163 & 67.248 & 0.987 & -163.386 & 165.712 \\
2 by 4 & 3.028 & 67.248 & 0.966 & -161.521 & 167.577 \\
3 by 4 & -9.547 & 67.248 & 0.892 & -174.096 & 155.002 \\
\hline
\end{tabular}

Std.Err (Standard Error), p (p-values).

Table 4 indicated that the temperature and the oxygen/ethanol ratio were statistically significant in the energy consumption of the ATR. The use of the temperature at its maximum level $\left(1000^{\circ} \mathrm{C}\right)$ increases the energy expenditure by the ATR, while the oxygen/ethanol ratio at its maximum level $(1.5 \mathrm{~mol} / \mathrm{mol})$ reduces energy consumption. We did not observe a statistically significant interaction effect between temperature and the oxygen/ethanol ratio for ATR energy consumption. The steam/ethanol ratio and the pressure were not statistically significant. With parameters of Tables 3 and 4, we perform a regression of statistically significant factors. The mathematical models obtained for hydrogen production and ATR energy consumption are shown in Eqs. 6 and 7, respectively.

$$
\text { Hydrogen Production }=2.462+1.334 T+0.303 R-0.530 R o-0.489 T R o \text {, }
$$

$$
\text { Energy Consumption }=-111.393+158.162 T-330.423 R o \text {, }
$$

Where:

T: temperature coded;

$\mathrm{R}$ : Steam/ethanol ratio coded;

Ro: Oxygen/ethanol ratio coded.

Table 5 shows ANOVA for hydrogen production and ATR energy consumption. 
Table 5. ANOVA for the model of hydrogen production by ethanol autothermal reform

\begin{tabular}{|c|c|c|c|c|c|}
\hline Factor: Hydrogen Producion & SS & df & MS & $\mathbf{F}$ & $p$ \\
\hline Temperature $\left({ }^{\circ} \mathrm{C}\right)$ & 28.483 & 1 & 28.483 & 251.706 & 0.000 \\
\hline Steam/ethanol $(\mathrm{mol} / \mathrm{mol})$ & 1.471 & 1 & 1.471 & 13.007 & 0.003 \\
\hline $\mathrm{O}_{2} /$ ethanol & 4.491 & 1 & 4.491 & 39.694 & 0.000 \\
\hline 1 by 4 & 3.836 & 1 & 3.836 & 33.901 & 0.000 \\
\hline Error & 1.357 & 12 & 0.113 & & \\
\hline Total SS & 39.641 & 16 & & & \\
\hline Factor: ATR Energy Consumption & SS & df & MS & $\mathbf{F}$ & $\mathbf{p}$ \\
\hline Temperature $\left({ }^{\circ} \mathrm{C}\right)$ & 400242 & 1 & 400242 & 40.963 & 0.000 \\
\hline $\mathrm{O}_{2} /$ ethanol $(\mathrm{mol} / \mathrm{mol})$ & 1746866 & 1 & 1746866 & 178.784 & 0.000 \\
\hline Error & 136791 & 14 & 9771 & & \\
\hline Total SS & 2283900 & 16 & & & \\
\hline
\end{tabular}

SS (sum-of-squares); df (degrees of freedom); MS (mean squares); $F$ ( $f$ ratio); $p$ ( $p$ values).

For hydrogen production, the $F_{\text {calculated }}(84.58) / F_{\text {tabulated }}(3.26)$ ratio was 25.94 . Therefore, the model is statistically significant since this ratio was greater than 1 [27]. For the ATR energy consumption model, the $F_{\text {calculated }}(109.87) / F_{\text {tabulated }}(3.74)$ ratio was 29.40 . Thus, this model was also statistically significant. The $R^{2}$ for the Eqs. 6 and 7 were 0.966 and 0.940 , respectively. Figure 4 graphically confirm the quality of the models obtained when comparing their predicted values with those obtained in the Aspen HYSYS simulations.
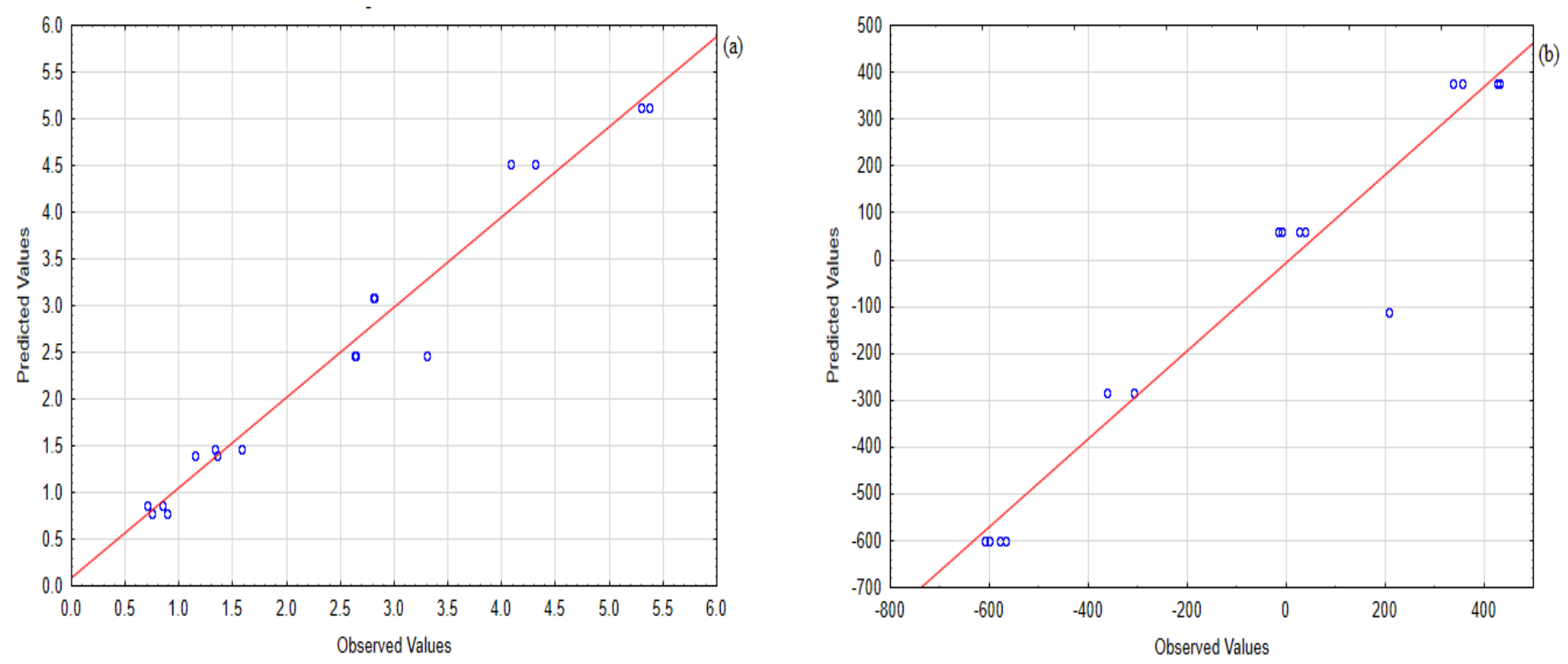

Figure 4. Comparison between the values predicted by the model with those obtained in the Aspen HYSYS simulations. (a) Hydrogen production from the ethanol autothermal reforming; (b) Energy consumption in the ATR from the ethanol autothermal reforming.

Figure $5(a ; b$ and $c)$ shows the response surfaces for hydrogen production, based on a combination of independent factors, Temperature $\mathrm{x}$ Steam/ethanol, Temperature $\times \mathrm{O}_{2} /$ ethanol, and Steam/ethanol $\mathrm{x}$ $\mathrm{O}_{2}$ /ethanol, respectively. Figure 5 (d) shows the response surface for ATR energy consumption from the combination of Temperature $\times \mathrm{O}_{2} /$ ethanol. 


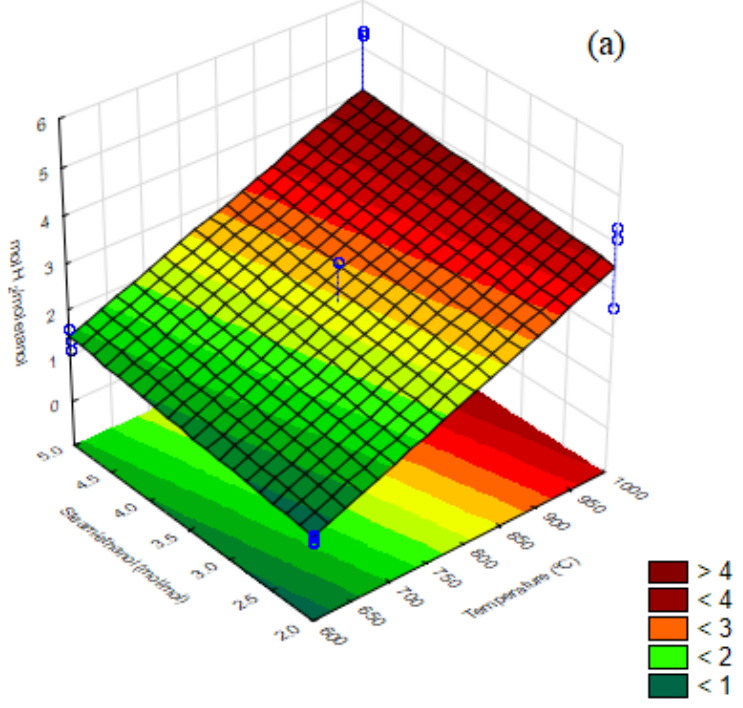

(c)

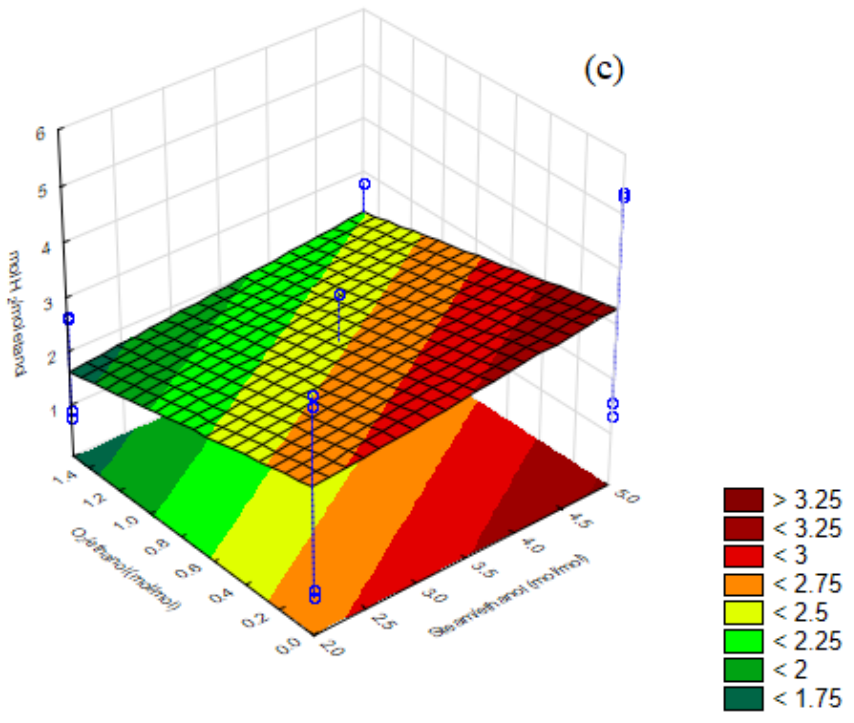

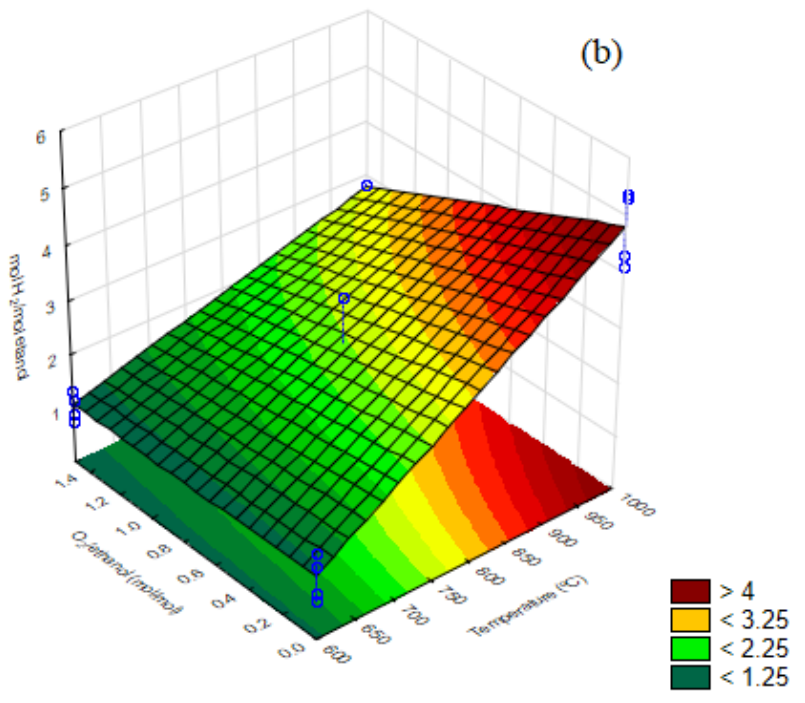

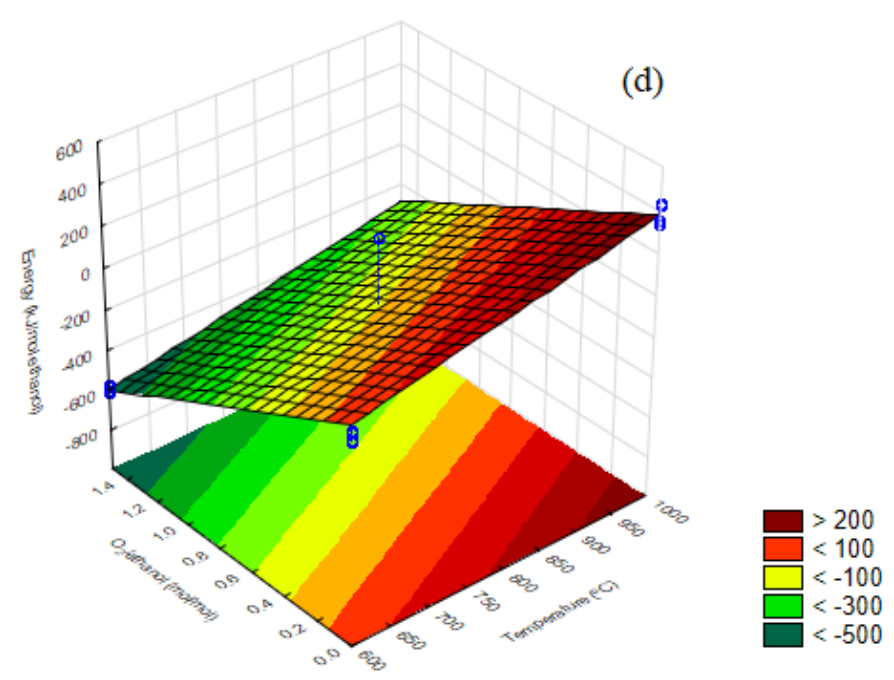

Figure 5. Response surfaces for the hydrogen production and for ATR energy consumption by the ethanol autothermal reforming. (a) $\mathrm{H}_{2}$ production: Temperature versus Steam/ethanol; (b) $\mathrm{H}_{2}$ production: Temperature versus $\mathrm{O}_{2} /$ ethanol; (c) $\mathrm{H}_{2}$ production: Steam/ethanol versus $\mathrm{O}_{2} /$ ethanol; (d) ATR energy consumption: Temperature versus $\mathrm{O}_{2} /$ ethanol.

The analysis of the response surfaces reinforces the idea that the maximum hydrogen production occurs at the maximum levels of temperature and steam/ethanol ratio $\left(1000{ }^{\circ} \mathrm{C}\right.$ and $\left.5 \mathrm{~mol} / \mathrm{mol}\right)$ and the minimum level of the $\mathrm{O}_{2} /$ ethanol ratio $(0 \mathrm{~mol} / \mathrm{mol})$. This result occurs because the hydrogen production decreases with the $\mathrm{O}_{2}$ /ethanol ratio increase and increases at higher temperatures. As the pressure was not statistically significant for the hydrogen production, it was fixed at its minimum value (20 bar).

For $1000 \stackrel{\circ}{\circ} \mathrm{C}, 5 \mathrm{~mol} / \mathrm{mol}$ steam/ethanol ratio, and $0 \mathrm{~mol} / \mathrm{mol} \mathrm{O}_{2} /$ ethanol ratio, we used Equation 6 and found $5.12 \mathrm{~mol} \mathrm{H} / \mathrm{mol}$ ethanol. These conditions were simulated in Aspen Hysys, and we found the production of $5.37 \mathrm{~mol} \mathrm{H} / \mathrm{mol}$ ethanol. Therefore, the error between the model and the simulated value is 4.66\%. Besides that, we used the same operational conditions in Equation 7 and found an energy consumption of $477.92 \mathrm{~kJ} / \mathrm{mol}$ ethanol. These operating conditions were simulated in Aspen HYSYS, and we obtained $430.92 \mathrm{~kJ} / \mathrm{mol}$ ethanol. Thus, the error between the value obtained with the model and the simulated is $10.91 \%$. These results are in agreement with the literature. Nimmas and coauthors [28] and Xue and coauthors [18] also found high conversion of ethanol and high hydrogen production efficiency (above $60 \%$ at 
the dry output current) from ethanol autothermal reform. In addition, we used our flowchart shown in Figure 1 to simulate some experimental conditions provided by other authors. For this, we used one case from [19] at $540{ }^{\circ} \mathrm{C}$ and $1 \mathrm{~atm}$ with steam/ethanol and $\mathrm{O}_{2} /$ ethanol ratios of $(9 \mathrm{~mol} / \mathrm{mol})$ and $(0.9 \mathrm{~mol} / \mathrm{mol})$, respectively. Besides, we simulated a second case from [20] at $540 \stackrel{\circ}{\circ} \mathrm{C}$ and $1 \mathrm{~atm}$ with steam/ethanol and O2/ethanol ratios of $(9 \mathrm{~mol} / \mathrm{mol})$ and $(0.7 \mathrm{~mol} / \mathrm{mol})$, respectively. The obtained errors were less than $3.90 \%$, proving that our assumptions are satisfactory.

In order to find the $\mathrm{O}_{2}$ /ethanol ratio that allows the ATR to operate in energy self-sufficiency, we apply the best conditions for the hydrogen production ( $1000{ }^{\circ} \mathrm{C}$ and $5 \mathrm{~mol} / \mathrm{mol}$ steam/ethanol ratio) in Equation 7 and equal it to 0 . Therefore, we find 0.86 for the $\mathrm{mol} \mathrm{O}_{2} / \mathrm{mol}$ ethanol ratio. The value obtained in Aspen HYSYS was $0.88 \mathrm{~mol} \mathrm{O} / 2 \mathrm{~mol}$ ethanol for the ATR to operate in energy self-sufficiency, that is, without requiring external energy. For the $\mathrm{O}_{2}$ /ethanol ratio, the error between the model and the simulated value is $2.27 \%$.

In this work, the errors found between values predicted by the models and those obtained by simulations are acceptable. For the conditions $\left(1000{ }^{\circ} \mathrm{C}, 20 \mathrm{bar}, 0.86 \mathrm{~mol} \mathrm{O} / 2 \mathrm{~mol}\right.$ ethanol ratio, and $5 \mathrm{~mol} / \mathrm{mol}$ steam/ethanol ratio) of ATR energy self-sufficiency, the hydrogen production was $3.95 \mathrm{~mol} \mathrm{H} / \mathrm{mol}$ ethanol. The comparison between the points of maximum hydrogen production $\left(1000^{\circ} \mathrm{C}, 20 \mathrm{bar}, 0 \mathrm{~mol} \mathrm{O} / \mathrm{mol}\right.$ ethanol ratio and $5 \mathrm{~mol} / \mathrm{mol}$ steam/ethanol ratio) and ATR energy self-sufficiency indicates that hydrogen production is reduced from 5.12 to $3.95 \mathrm{H}_{2} / \mathrm{mol}$ ethanol, that is, a drop of $22.85 \%$. In contrast, ATR energy consumption is reduced by $100 \%$.

From the analysis carried out, we observe that the pressure was not statistically significant for the hydrogen production for ethanol autothermal reforming. To the best of our knowledge, the scientific literature does not present data that included pressure in the studies. Therefore, we demonstrate that pressure is not statistically significant for the production of hydrogen in the range studied (20-30 bar). Thus, the pressure does not require precise control in industrial operations and can be fixed at its minimum value (20 bar) in order to guarantee greater operational safety to the process. Both for studies and industrial operations, temperature, steam/ethanol ratio, and $\mathrm{O}_{2}$ /ethanol ratio should be treated with greater importance concerning the process pressure.

To the best of our knowledge, the scientific literature does not present studies that identified negative interaction between temperature and $\mathrm{O}_{2}$ /ethanol ratio for hydrogen production, nor studies that found polynomial mathematical models for hydrogen production and ATR energy consumption for the ethanol autothermal reforming. In this paper, we identify the negative interaction effect between temperature and $\mathrm{O}_{2}$ /ethanol ratio that was taken into account in the polynomial models found for hydrogen production. Finally, we observe that with the obtained models it is possible to evaluate hydrogen production and ATR energy consumption in a precise and straightforward way, thus complementing the knowledge about the thermodynamics of the ethanol autothermal reforming.

\section{CONCLUSION}

In this paper, we simulated the ethanol autothermal reforming for hydrogen production. We carried out a complete factorial design for four variables (temperature, pressure, steam/ethanol ratio, and $\mathrm{O}_{2} /$ ethanol ratio) and simulations to assess significant factors, interactions between variables, and for obtaining polynomial mathematical models for hydrogen production and ATR energy consumption.

The industrial flowchart proposed in this study was validated from the similarity found between the behaviors of the response surfaces obtained with the behaviors presented by Rabenstein and Hacker [25]. From the analysis of the Pareto chart, we observed that there was a negative interaction between temperature and the $\mathrm{O}_{2}$ /ethanol ratio and that the steam/ethanol ratio was also statistically significant for hydrogen production. However, the pressure of the process was not statistically significant. In ATR energy consumption, we identified that only the temperature and the $\mathrm{O}_{2}$ /ethanol ratio were statistically significant. Thus, the pressure can be disregarded in statistical analysis for the development of mathematical models for hydrogen production and ATR energy consumption. Furthermore, in industrial cases, it is not necessary to strictly control the process pressure since moderate variations in pressure will not have a significant effect on the final production of hydrogen gas. More considerable attention should be paid to the study and control of temperature, steam/ethanol ratio, and $\mathrm{O}_{2}$ /ethanol ratio since these variables were statistically significant. Our analysis also allowed to obtaining of mathematical models for hydrogen production and ATR energy consumption. After verifying that the models are statistically significant, we used their equations and obtained

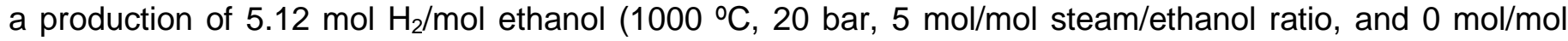
$\mathrm{O}_{2} /$ ethanol ratio). We also found an $\mathrm{O}_{2} /$ ethanol ratio of $0.86 \mathrm{~mol} / \mathrm{mol}$ for the ATR to achieve energy self- 
sufficiency. In these conditions, we found a production of $3.95 \mathrm{~mol} \mathrm{H}_{2} / \mathrm{mol}$ ethanol at $1000 \stackrel{\circ}{\circ}, 20$ bar, 5 $\mathrm{mol} / \mathrm{mol}$ steam/ethanol ratio. The comparison between these two situations showed that for ATR energy selfsufficiency, the process loses $22.85 \%$ of the hydrogen production. However, it reduced ATR energy consumption by $100 \%$.

In summary, we have demonstrated that the addition of oxygen in the ethanol steam reforming process can decrease energy consumption in the reforming reactor. However, this reduction in energy means a loss in the production of $\mathrm{H}_{2}$. Therefore, in order to decide between maximum $\mathrm{H}_{2}$ production or less costly conditions from an energy point of view, it is necessary to evaluate other issues (not included in the paper), such as the plant's production goals, the value of the $\mathrm{H}_{2}$ on the market, among others.

Funding: This study was financed in part by the Coordenação de Aperfeiçoamento de Pessoal de Nível Superior Brasil (CAPES) - Finance Code 001.

Acknowledgments: The authors would like to thank CAPES and the Postgraduate Program of Chemical Engineering at UFBA for supporting the research.

Conflicts of Interest: The authors declare no conflict of interest. The funders had no role in the design of the study; in the collection, analyses, or interpretation of data; in the writing of the manuscript, or in the decision to publish the results.

\section{REFERENCES}

1. Abe JO, Popoola API, Ajenifuja E, Popoola OM. Hydrogen energy, economy and storage: review and recommendation. Int J Hydrogen Energy. Jun 2019;44(29):15072-86.

2. Abokyi E, Appiah-Konadu P, Abokyi F, Oteng-Abayie EF. Industrial growth and emissions of $\mathrm{CO} 2$ in Ghana: The role of financial development and fossil fuel consumption. Energy Rep. Nov 2019;5:1339-53.

3. Sun Y, Shen C, Lai Q, Liu W, Wang DW, Aguey-Zinsou KF. Tailoring magnesium based materials for hydrogen storage through synthesis: Current state of the art. Energy Storage Mater. Jan 2018;10:168-98.

4. Sinigaglia T, Freitag TE, Kreimeier F, Martins MES. Use of patents as a tool to map the technological development involving the hydrogen economy. World Pat Inf. Mar 2019;56:1-8.

5. Mah AXY, Ho WS, Bong CPC, Hassim MH, Liew PY, Asli UA, Chemmangattuvalappil NG. Review of hydrogen economy in Malaysia and its way forward. Int J Hydrogen Energy. Mar 2019;44(12):5661-75.

6. Ren X, Dong L, Xu D, Hu B. Challenges towards hydrogen economy in China. Int J Hydrogen Energy. Dec 2020;45(59):32326-45.

7. Liu J. China's renewable energy law and policy: a critical review. Renewable Sust Energy Rev. Jan 2019;99:2129.

8. Miranda PE. Science and Engineering of Hydrogen-Based Energy Technologies: Hydrogen Production and Practical Applications in Energy Generation. 1st ed. Rio de Janeiro: Academic Press; 2018. 438 p.

9. Vita A, Pino L, Italiano C, Palella A. Steam Reforming, Partial Oxidation, and Autothermal Reforming of Ethanol for Hydrogen Production in Conventional Reactors. In: Basile A, Dalena AIF, Veziroğlu TN. Ethanol: Science and Engineering. 1st ed. New York: Elsevier; 2019. p. 159-91.

10. Pashchenko D. Combined methane reforming with a mixture of methane combustion products and steam over a Ni-based catalyst: An experimental and thermodynamic study. Energy. Oct 2019;185:573-84.

11. Gondal IA, Masood SA, Khan R. Green hydrogen production potential for developing a hydrogen economy in Pakistan. Int J Hydrogen Energy. Mar 2018;43(12):6011-39.

12. Calisan A, Ogulgonen CG, Yilmaz A, Uner D, Kincal S. Steam methane reforming over structured reactors under concentrated solar irradiation. Int J Hydrogen Energy. Jul 2019;44(34):18682-93.

13. Fahim MA, Al-Sahhaf TA, Elkilani AS. Introdução ao refino de petróleo. 1st ed. Rio de Janeiro: Editora Campus; 2012. 480 p.

14. Muritala IK, Guban D, Roeb M, Sattler C. High temperature production of hydrogen: Assessment of non-renewable resources technologies and emerging trends. Int J Hydrogen Energy. Oct 2010;45(49):26022-35.

15. Sayar A, Eskin N. Experimental and theoretical analysis of a monolith type auto-thermal reforming reactor. Int $\mathrm{J}$ Hydrogen Energy. Apr 2019;44(21):10232-49.

16. Fischer $C D$, Iribarren $O A$. Oxygen integration of autothermal reforming of ethanol with oxygen production, through ion transport membranes in countercurrent configuration. Comput Chem Eng. Apr 2017; 99:245-54.

17. Yamazaki Y, Maruko S, Komori S, inventors; Nippon Chemical Plant Consultant Co Ltd, assignee. Oxidative autothermal reformer and oxidative autothermal reforming method using the same. United States patent 7981372. $2011 \mathrm{Jul} 19$.

18. Xue Z, Shen Y, Li P, Pan Y, Li J, Feng Z, et al. Promoting effects of lanthanum oxide on the $\mathrm{NiO} / \mathrm{CeO} 2$ catalyst for hydrogen production by autothermal reforming of ethanol. Catal Commun. Apr 2018;108: 12-6. 
19. Greluk M, Słowik G, Rotko M, Machocki A. Steam reforming and oxidative steam reforming of ethanol over PtKCo/CeO2 catalyst. Fuel. Nov 2016;183:518-30.

20. Greluk M, Rybak P, Słowik G, Rotko M, Machocki A. Comparative study on steam and oxidative steam reforming of ethanol over 2KCo/ZrO2 catalyst. Catal Today. Mar 2015;242:50-9.

21. Baruah R, Dixit M, Basarkar P, Parikh D, Bhargav A. Advances in ethanol autothermal reforming. Renewable Sust Energy Rev. Nov 2015;51:1345-53.

22. García-García JA, Enríquez JG, Ruiz M, Arévalo C, Jiménez-Ramírez A. Software Process Simulation Modeling: Systematic literature review. Comput Stand Interfaces. Jun 2020;70:103425.

23. Brito JQ, Dias FDS, Cunha S, Ramos LP, Teixeira LS. Multiple response optimization of alkaline pretreatment of sisal fiber (Agave sisalana) assisted by ultrasound. Biotechnol Prog. Mar 2019;35(3): 1-9.

24. Graschinsky C, Giunta P, Amadeo N, Laborde M. Thermodynamic analysis of hydrogen production by autothermal reforming of ethanol. Int J Hydrogen Energy. Jul 2012;37:10118-24.

25. Rabenstein G, Hacker V. Hydrogen for fuel cells from ethanol by steam-reforming, partial-oxidation and combined auto-thermal reforming: A thermodynamic analysis. J Power Sources. Dec 2088;185(2):1293-304.

26. Hora L, Kelbichová V, Kikhtyanin O, Bortnovskiy O, Kubička D. Aldol condensation of furfural and acetone over MgAl layered double hydroxides and mixed oxides. Catal Today. Mar 2014;223:138-47.

27. Rodrigues MI, lemma AF. Experimental design and process optimization. 1st ed. Boca Raton: CRC Press; 2014. $336 \mathrm{p}$.

28. Nimmas T, Wongsakulphasatch $\mathrm{S}$, Cheng $\mathrm{CK}$, Assabumrungrat $\mathrm{S}$. Bi-metallic CuO-NiO based multifunctional material for hydrogen production from sorption-enhanced chemical looping autothermal reforming of ethanol. Chem Eng J. Oct 2020;398:125543.

2021 by the authors. Submitted for possible open access publication under the terms and conditions of the Creative Commons Attribution (CC BY NC) license (https://creativecommons.org/licenses/by-nc/4.0/). 